\title{
Do sparsely populated rural areas have the potential for the use of electric vehicles?
}

\author{
A. Mann, K. Klopsch, L. Bieker \& M. Wölki \\ German Aerospace Center, Institute of Transportation Systems, \\ Traffic Management, Germany
}

\begin{abstract}
After a hundred years of developing combustion engines for cars, electric mobility is on the horizon of reaching a technological turning point in the history of the mobility sector. The gear's electrification is a key element in sustainable mobility. The dependence on oil will be reduced and emissions will be minimized. Therefore, on May the $3^{\text {rd }} 2013$ the National Platform for Electric Mobility (NPE) was launched in Berlin, by the Federal Chancellor in order to boost electric mobility in Germany and accelerate the commercialization of innovative electric vehicles. By 2020, one million electric cars shall be driving in Germany. Demonstration activities, fleet trials and pilot operations are performed in various cities around the world. However, do sparsely populated, rural areas also have the potential for the use of electric vehicles? In applying the example of Germany, this study recorded the current situation of households and their needs concerning mobility in small towns and rural regions. These mobility requirements were compared with the capabilities of electric vehicles. Furthermore, the following questions were answered: How many people live in rural areas? How is the age structure? What is the modal split? Which patterns of commuting can be identified? Do the licensed driver's quota, the level of motorization and the availability of private parking differ from the urban space? Finally, do these factors facilitate or impede the use of electric vehicles in small towns and rural areas? These considerations were followed by the development of possible sale scenarios, which are based on the cost structure and range of electric vehicles on the one hand, and conventional vehicles with combustion engine on the other hand. Finally, the potential use of electric vehicles in small towns and rural areas is assessed, as well as its contribution to the objective of
\end{abstract}


the federal government to have one million electric vehicles on Germany's streets by 2020 .

Keywords: electric vehicles, sustainable mobility, sparsely populated and rural areas, potential analyses, break even analysis, e-mobility.

\section{Introduction}

Mobility is the basis of wealth and social participation in modern society. Electric mobility is on the horizon of being a technological turning point in the history of the mobility sector since it offers a chance to reduce the dependence on fossil fuels while minimizing emissions - despite rising traffic volumes.

New technologies, such as alternative drives, are the key to success. Electric mobility, in particular, provides a great opportunity that must be seized for the benefit of the citizens, the climate and the industry. Germany, therefore, is aimed at becoming a lead market and lead supplier for electric mobility. The goal is that one million electric vehicles will be driving on German roads by 2020 [1].

Electric mobility is indeed a very popular topic, but it is almost exclusively discussed in connection with major cities. However, surely the success of electric vehicles cannot be achieved by cities and towns alone. Without sparsely populated rural areas and their effective support, this success is impaired or even absent. Electric mobility brings opportunities as well as challenges for sparsely populated rural areas.

Therefore, the presented analysis deals with the possible use of electric mobility in rural communities and small towns. It sums up the present situation of households in sparsely populated rural areas and discusses the present problem of a limited range of electric vehicles for use in these regions. Furthermore, possible sales scenarios of electric vehicles in rural areas and small towns are also investigated. Finally, the cost-effectiveness of electric vehicles is considered, since the initial purchase of such a vehicle causes essential extra costs.

\section{Methodology}

For our investigations, it is necessary to determine the amount of people that are to be considered as a target group. The investigation is based mainly on a characterization of the socio-demographic attributes as well as selected mobility indicators. There is also the consideration of different forecasts for petrol, diesel and electricity price development and the development of the cost of diesel and battery-operated electric vehicles. The aim here is to identify the potential of electric mobility in rural areas and small towns for the years 2015 to 2030 based on the determined characteristics of the study group.

In order to achieve this, three scenarios are considered. The first is an optimistic scenario, in which it is assumed that supporting factors for the use of electric cars in sparsely populated, rural areas occur. Among these are high petrol prices, in relation to lower electricity prices, or the inclusion of parking spaces in close proximity to properties. Secondly, the pessimistic scenario assumes 
unfavorable factors such as low fuel and high electricity prices for the use of electric vehicles in the study area. Finally, the medium scenario is the average of the other two scenarios.

\section{Assumptions}

\subsection{Population}

In this article, sparsely populated, rural areas are understood as small towns and rural communities with a population density below 200 inhabitants $/ \mathrm{km}^{2}$ and an overall population below 20,000 inhabitants. This is in accordance with the classification for city and community types defined by the Bundesinstitut für Bau-, Stadt- und Raumforschung BBSR (Federal Institute for Building, Urban Affairs and Spatial Development). As a result, nearly 32,960,000 people in Germany live in the study area [2]. This corresponds to $40.3 \%$ of the total German population.

Considering the age structure of the population in the study area, there are hardly any differences in comparison to large and medium cities. Only the population demographic of those aged $65+$ years are over-represented in sparsely populated, rural communities (21\%) compared to urban areas (17\%) [3].

\subsection{Car ownership and parking situation}

This demographic of nearly 33 million people have about 20,962,400 private cars available to them. This accounts for $52.4 \%$ of the car fleet in Germany [3]. The percentage of people with a driving license is smaller in large and medium cities compared to rural areas. The high rates of holding a license within rural communities and small towns indeed shows how important holding a driving license and individual mobility is [3].

The parking situation at home is a contributing factor to electric mobility. In particular, when people wish to use their own car and when a car-sharing model as an alternative is not available, a dedicated parking space with a plug to charge the battery is required. A personal parking space is favored, as the electric car can be charged daily, and thus the full power of the battery is available for the required daily distance. Therefore, intermediate stops for recharging the battery are not required as long as the maximum range of the electric vehicle is not exceeded [4]. Using data from [3], the parking space situation was investigated. For $16,701,000$ vehicles $(79.67 \%)$ there is a parking space on the owner's private property, while for the additional 3,912,000 vehicles (18.66\%), parking is available in the immediate vicinity [3]. In the optimistic scenario, these two groups add up to 20,612,000 vehicles that have a charging option at their personal parking space. In contrast, the pessimistic scenario is comprised of only the first group of $16,701,000$ vehicles, compared to $18,657,000$ vehicles in the medium scenario. 


\subsection{Mobility factors}

The modal split describes the behavior of people with respect to their choice of transport modes for different trip purposes. The three most occurring trip types shopping, work, and recreation - do not show any significant differences between the types of areas [3]. The consideration of the modal split provides more information on area-specific differences. In sparsely populated, rural areas and small towns, the share of motorized individual traffic (MIV) is $63 \%$. In core cities and towns, the share of MIV is only $48 \%$.

The remaining $37 \%$ of the selected transport modes within the study area are distributed to $31 \%$ pedestrians or those on bicycles and only $6 \%$ remains for public transport use. For electrical mobility, this means that the vast majority of trips in the study area are performed with the availability of private cars.

In everyday life, the majority of trips are no longer than $20 \mathrm{~km}$ and for $95 \%$ of the vehicles the daily mileage is less than $100 \mathrm{~km}$ (Figure 1) [5]. Therefore, everyday mileage could be well covered with electric vehicles, especially since today's minimum range of $80 \mathrm{~km}$, given by NEDO [14], is bigger. A study has shown that the daily travel distance in rural areas hardly differs from the routes of the city's population [4].

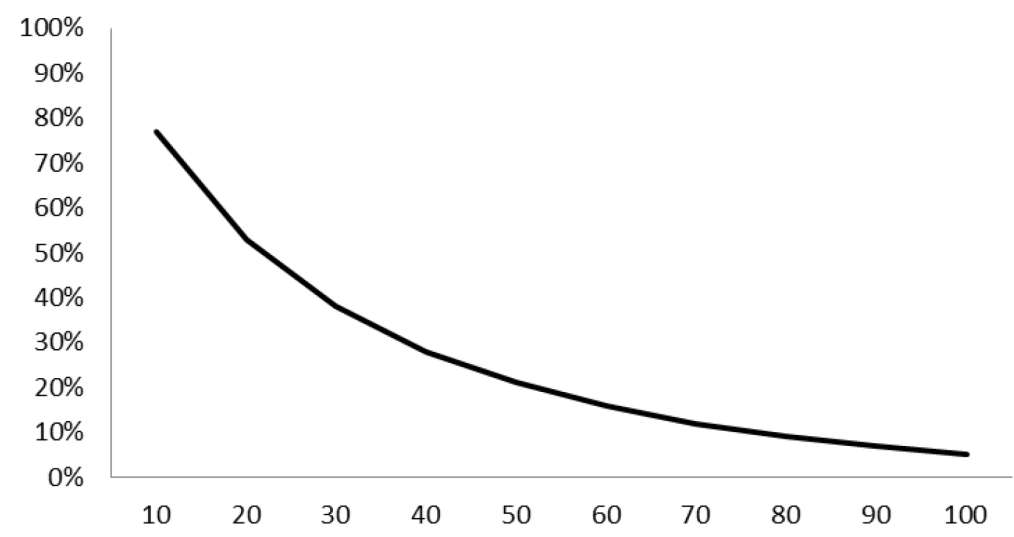

Figure 1: Minimal daily travel distance in Germany [5].

\subsection{Energy costs}

Not least due to the increase of fossil fuel prices, the demand for alternative drives is becoming stronger. The petrol and diesel prices in Germany are subject to an average annual increase of 4\% (Figure 2) with diesel fuel being 13 euro cents $(15 \%)$ cheaper on average than premium petrol.

There are several forecasts for the future development of fuel prices. The most important ones [7-12], are listed in Table 1. Herein, not necessarily all stated values for the years 2015, 2020, 2025 and 2030 were originally given. Therefore, the available numbers (in bold, Table 1) were inter- and extrapolated. 


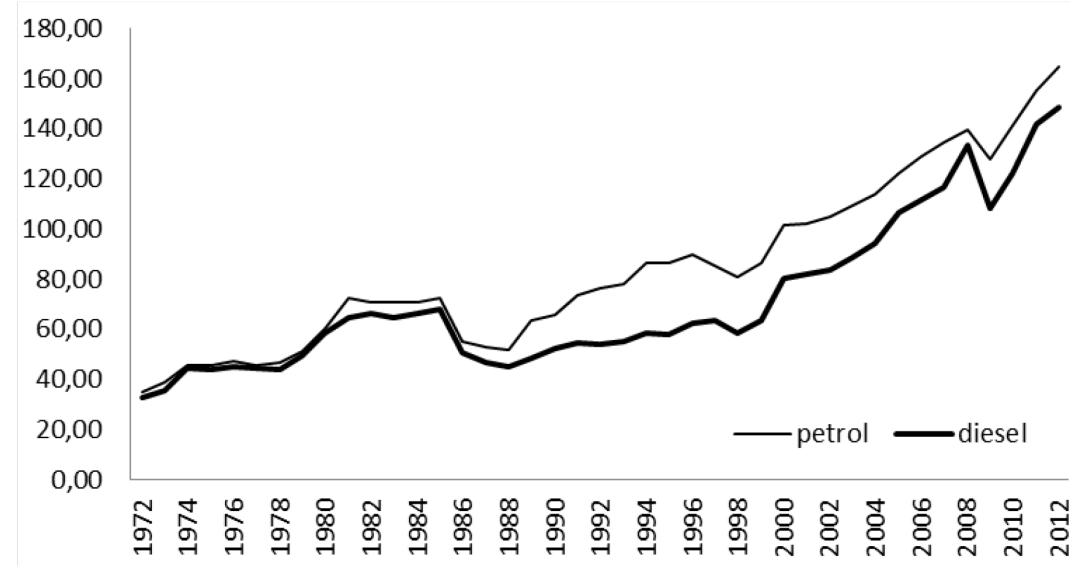

Figure 2: Development of fuel prices in Germany from 1972 to 2012 in euro cent/litre [6].

Table 1: Prediction of the development of the petrol price in EUR/litre.

\begin{tabular}{|ll|c|c|c|c|}
\hline Prediction & 2015 & 2020 & 2025 & 2030 \\
\hline$[7]$ & EWI/Prognos 2005 & $\mathbf{1 . 0 0 0}$ & $\mathbf{1 . 0 8 0}$ & $\mathbf{1 . 1 5 0}$ & $\mathbf{1 . 2 1 0}$ \\
\hline$[8]$ & EWI/Prognos 2006 - high price & 1.200 & $\mathbf{1 . 2 6 4}$ & 1.328 & $\mathbf{1 . 3 9 2}$ \\
\cline { 2 - 6 } & EWI/Prognos 2006 - low price & 1.120 & $\mathbf{1 . 1 5 0}$ & 1.180 & $\mathbf{1 . 2 1 0}$ \\
\hline$[9]$ & EWI/Prognos 2011 & $\mathbf{1 . 4 5 0}$ & $\mathbf{1 . 5 2 0}$ & $\mathbf{1 . 6 2 0}$ & $\mathbf{1 . 7 1 0}$ \\
\hline$[10]$ & mobility 2025 & $\mathbf{1 . 6 1 0}$ & $\mathbf{1 . 7 7 0}$ & $\mathbf{1 . 9 5 0}$ & $\mathbf{2 . 1 5 0}$ \\
\hline$[11]$ & energy prognosis 2009 & 1.335 & $\mathbf{1 . 3 5 0}$ & 1.365 & $\mathbf{1 . 3 8 0}$ \\
\hline$[12]$ & passenger car market till 2040 & 1.520 & $\mathbf{1 . 5 3 0}$ & 1.540 & $\mathbf{1 . 5 5 0}$ \\
\hline
\end{tabular}

From some of these studies and comparable works [13] information on the development of the electricity price can be retrieved as well (Table 2). Here the same method of interpolation as for the fuel prices has been applied.

Table 2: Prediction of the development of the electricity price in euro cent $/ \mathrm{kWh}$.

\begin{tabular}{|ll|c|c|c|c|}
\hline Prediction & 2015 & 2020 & 2025 & 2030 \\
\hline$[7]$ & EWI/Prognos 2005 & 16.0 & $\mathbf{1 6 . 0}$ & 16.1 & $\mathbf{1 6 . 1}$ \\
\hline$[8]$ & EWI/Prognos 2006 & 16.3 & $\mathbf{1 6 . 3}$ & 16.4 & $\mathbf{1 6 . 4}$ \\
\hline$[13]$ & EWI 2008 - high price & 21.3 & $\mathbf{2 0 . 8}$ & 21.0 & $\mathbf{2 0 . 2}$ \\
\cline { 2 - 6 } & EWI 2008 - low price & 19.8 & $\mathbf{1 9 . 6}$ & 20.0 & $\mathbf{2 0 . 0}$ \\
\hline \multirow{2}{*}[9]{} & EWI/Prognos 2011 - scenario a) & 21.6 & $\mathbf{2 2 . 6}$ & 23.2 & $\mathbf{2 3 . 0}$ \\
\cline { 2 - 6 } & EWI/Prognos 2011 - scenario b) & 21.2 & $\mathbf{2 2 . 1}$ & 22.7 & $\mathbf{2 2 . 5}$ \\
\hline \multirow{2}{*}[11]{} & energy prognosis 2009 - reference & 23.8 & $\mathbf{2 3 . 4}$ & 23.0 & $\mathbf{2 2 . 6}$ \\
\cline { 2 - 6 } & energy prognosis 2009 - scenario a) & 21.4 & $\mathbf{2 1 . 8}$ & 22.2 & $\mathbf{2 2 . 6}$ \\
\cline { 2 - 6 } & energy prognosis 2009 - scenario b) & 21.4 & $\mathbf{2 1 . 2}$ & 21.1 & $\mathbf{2 0 . 9}$ \\
\hline
\end{tabular}


The forecasts in Table 1 and 2, and the 15\% price advantage of the diesel fuel, result in three predictions for diesel and electricity prices from the present to 2030. Pessimistically, the lowest prices for petrol and diesel are both assumed together with the highest electricity price. In the optimistic scenario, this is reversed. In the medium scenario, again the average values are used in each case (Table 3).

Table 3: Petrol, diesel and electricity prices in EUR/litre respective EUR/kWh for the three scenarios.

\begin{tabular}{|l|c|c|c|c|}
\hline & 2015 & 2020 & 2025 & 2030 \\
\hline Pessimistic scenario & & & & \\
\hline Petrol & 1.000 & 1.080 & 1.150 & 1.210 \\
\hline diesel & 0.853 & 0.921 & 0.981 & 1.032 \\
\hline electricity & 0.238 & 0.234 & 0.232 & 0.230 \\
\hline Medium scenario & & & & \\
\hline Petrol & 1.319 & 1.381 & 1.448 & 1.515 \\
\hline Diesel & 1.125 & 1.178 & 1.235 & 1.292 \\
\hline Electricity & 0.203 & 0.204 & 0.206 & 0.205 \\
\hline \hline Optimistic scenario & & & & \\
\hline Petrol & 1.610 & 1.770 & 1.950 & 2.150 \\
\hline Diesel & 1.373 & 1.510 & 1.663 & 1.834 \\
\hline Electricity & 0.160 & 0.160 & 0.161 & 0.161 \\
\hline
\end{tabular}

\subsection{Vehicle concepts and costs}

The Battery-Electric Vehicle (BEV) is based on an all-electric concept. Not only the drive train, but also the driving power, is $100 \%$ provided by a battery. The range of all-electric vehicles is expected to increase from $120 \mathrm{~km}$ in the year 2015 to $480 \mathrm{~km}$ in 2030 [14].

The PHEV (Plug-in Hybrid Electric Vehicle) is a concept that has so far been classified as a bridging technology. There is a battery in the vehicle that can be charged by an external power source before driving. This battery lasts, on average, distances of about $20-30 \mathrm{~km}$ in the all-electric mode. During the trip, the breaking energy is fed back into the battery (recuperation). Once the battery is discharged completely, an internal combustion engine is started, which is directly connected to the drive train. Therefore, with such a vehicle, the achieved range is equal to that of a conventional vehicle [15].

The REEV (Range Extended Electric Vehicle) is a concept that has hybrid roots. The powertrain of the REEV is, in contrast to the PHEV, driven by electricity and the braking energy is recuperated as with the PHEV. Thus, the internal combustion engine works as a unit, which generates electricity for charging the battery, once the battery is depleted [15]. The electric range is $60 \mathrm{~km}$ for the Ampera model of the Opel/Vauxhall brand while its extended range lies over $500 \mathrm{~km}$ [16]. 
The acquisition costs of new vehicles are compared, since a second-hand market of electric vehicles is yet non-existent. The National Platform for Electric Mobility (NPE) gives the corresponding values for the year 2020 (bold) as shown in Table 4 [17]. The prices for the other years were calculated by the authors.

Table 4: Net list prices in EUR for vehicles according to vehicle categories [17] and their share of the current car fleet [18].

\begin{tabular}{|c|c|c|c|c|c|c|}
\hline Vehicle Category & Portion & Drive train & 2015 & 2020 & 2025 & 2030 \\
\hline Mini (Class A0) & $6.0 \%$ & \multirow[t]{2}{*}{ Petrol } & \multirow[t]{2}{*}{11,047} & \multirow[t]{2}{*}{11,176} & \multirow[t]{2}{*}{11,176} & \multirow[t]{2}{*}{11,176} \\
\hline Small (Class A) & $20.5 \%$ & & & & & \\
\hline Compact (Class B) & $27.2 \%$ & BEV & 18,633 & 16,720 & 15,873 & 15,027 \\
\hline \multirow{2}{*}{ Medium-sized (Class C) } & \multirow{2}{*}{$18.3 \%$} & Diesel & 19,644 & 19,702 & 19,702 & 19,702 \\
\hline & & Petrol REEV & 26,558 & 24,725 & 23,798 & 22,872 \\
\hline Upper m & $5.4 \%$ & Diesel & 33,576 & 33,734 & 33,734 & 33,734 \\
\hline Cross-country (Class D) & $4.8 \%$ & Petrol PHEV & 39,110 & 37,860 & 37,255 & 36,650 \\
\hline
\end{tabular}

These values are used for the medium scenario. The optimistic and pessimistic scenarios each differ by $5 \%$ to the medium scenario. Currently, the fuel consumption for the 10 most fuel-efficient passenger car models (Class A B) are at 4.0 liters $/ 100 \mathrm{~km}$ for petrol and 3.3 liters $/ 100 \mathrm{~km}$ for diesel cars and $12.7 \mathrm{kWh} / 100 \mathrm{~km}$ for electric vehicles [19]. The assumptions used for the development of specific fuel consumption in the transport sector [20] see savings in the future for all types of mobility means. Therewith, consumption characteristics will be reduced by 2030 (Table 5).

Table 5: Development of consumption for the most fuel-efficient passenger cars.

\begin{tabular}{|l|c|c|c|c|c|}
\hline Drive technology & 2013 & 2015 & 2020 & 2025 & 2030 \\
\hline Petrol $($ liter $/ 100 \mathrm{~km})$ & 4.0 & 3.8 & 3.4 & 2.8 & 2.4 \\
\hline Diesel $($ liter $/ 100 \mathrm{~km})$ & 3.3 & 5.5 & 4.7 & 3.9 & 3.6 \\
\hline Electricity $(\mathrm{kWh} / 100 \mathrm{~km})$ & 12.7 & 12.6 & 12.3 & 11.2 & 10.3 \\
\hline
\end{tabular}

The operation costs excluding fuel costs in the year 2020 are expected at $0.046 \mathrm{EUR} / 100 \mathrm{~km}$ (electric vehicle) and $0.056 € / 100 \mathrm{~km}$ (petrol/diesel) [21]. For the combination of all types of driving means, the operating costs of $0.061 € / 100 \mathrm{~km}$ are assumed.

\section{Evaluation}

The potential (Figure 3) for electric vehicles in sparsely populated rural areas is obtained by assuming a holding period of 5.6 years of new cars [22], a share of new registrations on car ownership [23] and [24] an average of 7.5\%. 


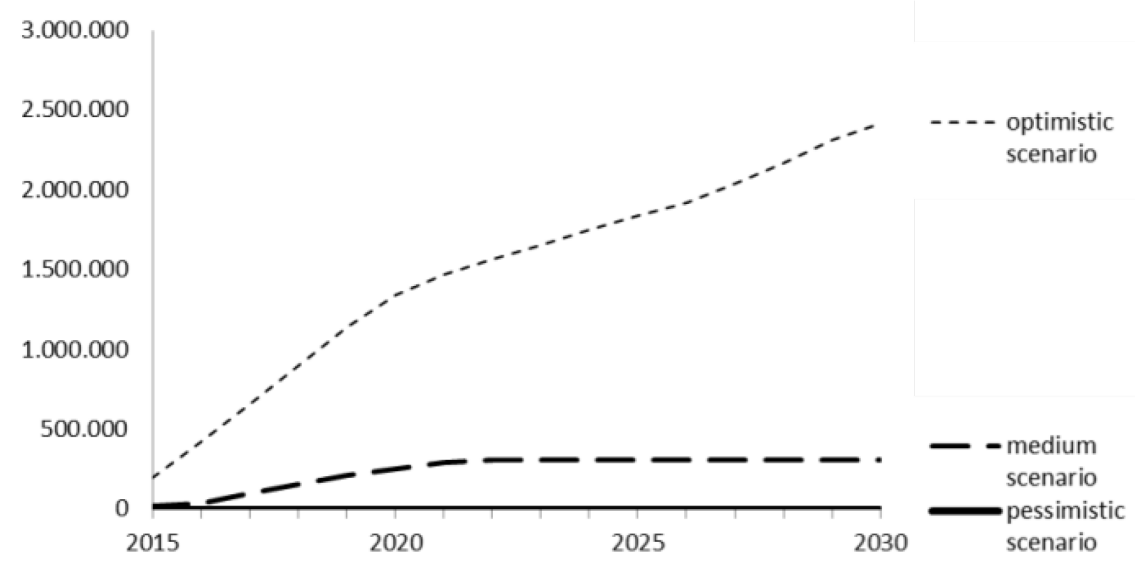

Figure 3: Potential of electric vehicles (units) in sparsely populated, rural areas for the years 2015-2030.

Therefore, the delta of $C=\operatorname{costs}(c=$ consumption, $o=$ operation, $i=$ investment, see eqn (1)) between electric and conventional vehicles $(v c=$ vehicle concept) was evaluated under the conditions of daily travel distance $(t d)$ (see eqn (2)). The consumption costs are depending on petrol, diesel and electricity prices as well as the development of consumption (Tables 3 and 5).

$$
\begin{gathered}
\Delta C=C(\text { electric vehicle })-C(\text { conventional vehicle }) \\
C=c(t d, v c)+o(t d, v c)+i(v c)
\end{gathered}
$$

The break-even point identifies the daily travel distance when the $\Delta \mathrm{C}<0$. Therefore, the maximum amount of cars that could benefit from electric vehicle concepts can be investigated. The potential is limited by the available parking space (see section 3.2 Car ownership and parking situation) and the percentage of new acquisition (7.5\%). As a result of this calculation the amount of electric vehicles driving in Germany's small towns and rural communities can be predicted.

\subsection{Pessimistic scenario}

If one assumes low prices for vehicles with internal combustion engines and (as in Table 5) in relation to more inhibiting factors for the use of electric vehicles such as low petrol and diesel prices, then it turns out that the use of electric vehicles in rural areas is not a cost-effective alternative. The investment cost of $\mathrm{BEV}, \mathrm{PHEV}$ and REEVs exceed the comparable costs for petrol (class A/B), as well as diesel vehicles (Class $\mathrm{C}$ and $\mathrm{D})$. 


\subsection{Medium scenario}

Assuming average forecasts - as neither inhibitory nor promoting factors for the use of electric vehicles - so we compare BEV to petrol vehicles (Class A/B) as an economic alternative for car users with a daily mileage of more than $150 \mathrm{~km}$ per day. Only from 2017 is the maximum range of BEV larger than the break-even point (Figure 4).

For the other vehicle concepts, the break-even point shifts from $220 \mathrm{~km}$ to $90 \mathrm{~km}(\mathrm{REEV})$ respectively from $230 \mathrm{~km}$ to $140 \mathrm{~km}$ (PHEV).

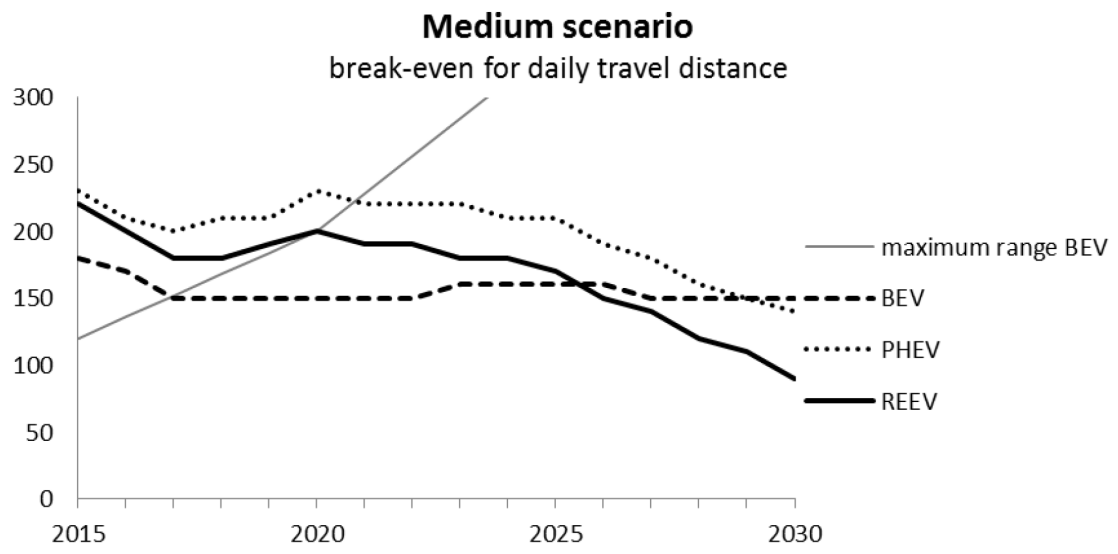

Figure 4: Break-even point in $\mathrm{km}$ for electric vehicles 2015-2013 (medium scenario).

If we now consider the proportion of vehicles with a daily mileage of $90 \mathrm{~km}$ or more (up to $7 \%$ ) then the potential results for electric vehicles in rural areas of 20,000 vehicles in 2015 rise to 312,000 vehicles in 2030 (Figure 3).

\subsection{Optimistic scenario}

If one considers this in relation to the more predisposing factors for the use of electric vehicles in rural areas, so all three considered types of driving are economic alternatives to petrol and diesel. The break-even for BEV compared to the petrol vehicles of category A/B occurs after 50 to $90 \mathrm{~km}$ daily mileage (Figure 5). Taking into account the proportion of vehicles with appropriate daytime driving performance $(7 \%$ to $21 \%)$ and the percentage of vehicles of Class A/B (mini, subcompact and compact cars/53.7\%), the result is the potential for having 58,000 electric vehicles in rural areas in 2015 and up to 874,000 vehicles in 2030 . 


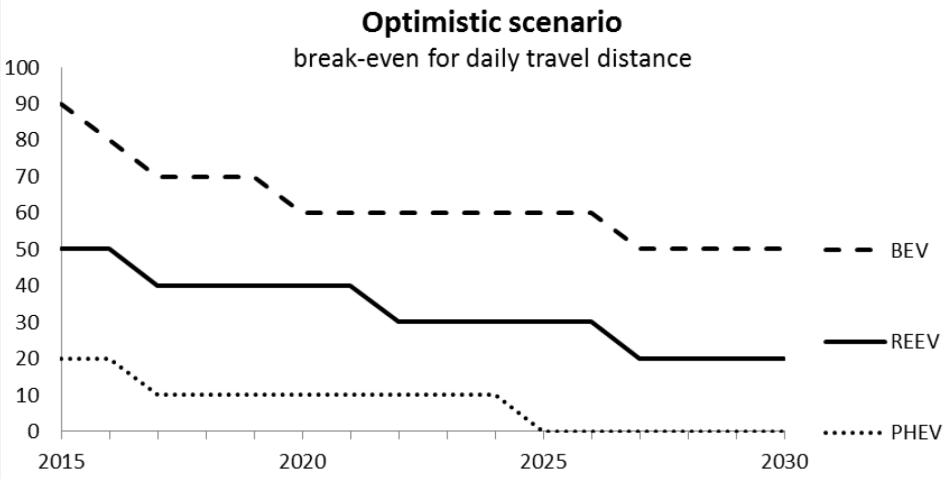

Figure 5: The break-even point in $\mathrm{km}$ for electric vehicles 2015-2013 (optimistic scenario).

For the other vehicle concepts the break-even point shifts from $50 \mathrm{~km}$ to 20 $\mathrm{km}$ (REEV) respectively from $20 \mathrm{~km}$ to $0 \mathrm{~km}$ (PHEV).

Considering now the proportion of vehicles with a daily mileage of $50 \mathrm{~km}$ or more (up to $21 \%$ ) then a potential of electric vehicles results in rural area of 201,000 vehicles in 2015 up to 2,416,000 vehicles in 2030 (Figure 3).

\section{Summary}

Depending on how the framework conditions for electric vehicles will change over time, sparsely populated, rural areas are a potential for this type of vehicle. The high number of available parking spaces and thus charging facilities at people's residences as well as the high rate of driving licenses held and the high proportion of private transport in the modal split are extremely favorable conditions for the use of electric vehicles in the study area. This investigation shows that at intermediate assumptions, the rural area can make only a small contribution to the goal of the federal government to have a million electric vehicles on German roads by 2020. With this goal, there should be approximately 524,000 electric vehicles in small towns and rural communities on the streets in 2020. This goal will not be achieved at the median forecast by approximately 257,000 electric vehicles.

The investigation has also shown that by 2020 , approximately 524,000 electric vehicles and more could drive in the study area. This requires favorable factors, such as low power and cost of electric vehicles. This can be achieved, for example, by transfers from the state.

However, this optimistic scenario also shows that even with very reasonable assumptions, there is no absolute advantage of vehicles with electric over combustion engines. In the important segment of the mini, small and compact cars $(53.7 \%)$ and at a daily mileage below $50 \mathrm{~km}(79 \%)$, the BEV is not convincing compared to economical petrol engines. 


\section{References}

[1] Bundesministerium für Verkehr, Bau und Stadtentwicklung Elektromobilität - Deutschland als Leitmarkt und Leitanbieter, Berlin, pp. 4, 2011

[2] Bundesinstitut für Bau-, Stadt- und Raumforschung, Laufende Raumbeobachtung des BBSR, Laufende Stadtbeobachtung Raumabgrenzungen, Stadt- und Gemeindetypen in Deutschland, 2013

[3] Bundesministerium für Verkehr, Bau und Stadtentwicklung, Mobilität in Tabellen, Webanwendung zur Auswertung der Erhebung Mobilität in Deutschland 2008 (MiD 2008)

[4] PricewaterhouseCoopers Aktiengesellschaft Wirtschaftsprüfungsgesellschaft, Elektromobilität - Normen bringen die Zukunft in Fahrt, pp. 44, 2012

[5] Öko-Institut, Das Mobilitätsverhalten der Deutschen: Tagesfahrleistung im Alltag, MID 2008/Auswertungen im Rahmen von OPTUM 2011

[6] Statistisches Bundesamt, Jährliche Verbrauchspreise für Mineralölprodukte 1950-2011 (inkl. MwSt) [ct./l]

[7] W. Schulz, M. Bartels, C. Gatzen, D. Lindenberger, F. Müsgens, M. Peek, A. Seelinger, D. Steuber, R. Wissen, P. Hofer, A. Kirchner, J. Scheelhaase, M. Schlesinger, Energiereport IV, Die Entwicklung der Energiemärkte bis zum Jahr 2030, Energiewirtschaftliche Referenzprognose, Köln and Basel, pp. IX, 2005

[8] D. Lindenberger, M. Bartels, A. Seelinger, R. Wissen, P. Hofer, M. Schlesinger, Auswirkungen höherer Ölpreise auf Energieangebot und nachfrage, Ölpreisvariante der Energiewirtschaftlichen Referenzprognose 2030, Köln and Basel, pp. X-XI, 2006

[9] Dr. M. Schlesinger, P. Hofer, Dr. A. Kirchner, Dr. A. Piégsa, S. Strassburg, PD Dr. D. Lindenberger, M. Fürsch, R. Malischek, S. Nagl, T. Panke, J. Trüby, Dr. C. Lutz, Dr. O. Khoroshun, Dr. U. Lehr, Energieszenarien 2011, Basel, Köln and Osnabrück, pp. 3 and 43, 2011

[10] Dr. M. Horn, Dr. -Ing. U. Kunert, D. Kalinowska, J. Kloas, R. Ochmann, Dr, E. Schulz, Mobilität 2025, Der Einfluss von Einkommen, Mobilitätskosten und Demografie, Anhang 3: Die Mobilitätskosten im Jahr 2025, Berlin, pp. 19, 2008

[11] U. Fahl, M. Blesl, A. Voß, P. Achten, D. Bruchof, B. Götz, M. Hundt, S. Kempe, T. Kober, R. Kuder, R. Küster, J. Lambauer, M. Ohl, U. Remme, N. Sun, V. Wille, S. Wissel, I. Ellersdorfer, F. Kesicki, M. Frondel, P. Grösche, M. Peistrup, N. Ritter, C. Vance, T. Zimmermann, A. Löschel, G. Bühler, T. Hoffmann, T. Mennel, N. Wölfing, Die Entwicklung der Energiemärkte bis 2030, Energieprognose 2009, Berlin, pp. 4-6, 2010

[12] J. Brokate, E. D. Özdemir, U. Kugler, Der PKW-Markt bis 2040: Was das Auto von morgen antreibt, Szenario-Analyse im Auftrag des Mineralölwirtschaftsverbandes, Stuttgart, pp. 22, 2013 
[13] D. Lindenberger, M. Bartels, F. Borggrefe, D. Bothe, R. Wissen, B. Hildebrand, H. G. Buttermann, M. Bleuel, Studie Energiewirtschaftliches Gesamtkonzept 2030, Endbericht, Köln and Berlin, pp. XVIII, 2008

[14] NEDO, Next Generation Vehicle Storage Battery Development Roadmap, Technology Development Roadmap for Secondary Batteries for Automobiles - Popularity and contribution of PHEV and EV, 2008

[15] O. S. Kaiser, S. Meyer, J. Schippl, Elektromobilität, ITA-Kurzstudie, Düsseldorf, pp. 29, 2011

[16] R. V. Helmolt, 9. Kaiserslauterer Forum 2010: Infrastruktur 2030 - Neue Wege für Rheinland-Pfalz, Elektrische Mobilität mit Batterie - und Brennstoffzellenfahrzeugen, Kaiserslautern, pp. 7, 2010

[17] Nationale Plattform Elektromobilität (NPE), Zweiter Bericht der Nationalen Plattform Elektromobilität Anhang, Berlin, pp. 28, 2011

[18] Kraftfahrzeugbundesamt, Bestand an Personenkraftwagen am 1. Januar 2013 gegenüber 1. Januar 2012 nach Segmenten und Modellreihen (Zulassungen ab 1990), pp. 1-6

[19] DAT Deutsche Automobil Treuhand $\mathrm{GmbH}$, Leitfaden über den Kraftstoffverbrauch, die $\mathrm{CO}_{2}$-Emmissionen und den Stromverbrauch aller neuen Personenkraftwagenmodelle, die in Deutschland zum Verkauf angeboten werden, pp. 68, 2013

[20] J. Nitsch, T. Pregger, T. Naegler, D. Heide, D. L. de Tena, F. Trieb, Y. Scholz, K. Nienhaus, N. Gerhardt, M. Sterner, T. Trost, A. v. Oehsen, R. Schwinn, C. Pape, H. Hahn, M. Wickert, B. Wenzel, Langfristszenarien und Strategien für den Ausbau der erneuerbaren Energien in Deutschland bei Berücksichtigung der Entwicklung in Europa und global, Schlussbericht, pp. 71, 2012

[21] H. Baum, J. Dobberstein, B. Schuler, Kosten-Nutzen-Analyse der Elektromobilität, Köln, 2011

[22] S. Trede, Das AUTOHAUS Extra, DAT-Report 2012, München, pp. 6, 2012

[23] Statistisches Bundesamt, Neuzulassungen von Kraftfahrzeugen in Deutschland, 2009-2012

https://www.destatis.de/DE/ZahlenFakten/Wirtschaftsbereiche/TransportV erkehr/UnternehmenInfrastrukturFahrzeugbestand/Tabellen/Neuzulassung en.html

[24] Statistisches Bundesamt, Fahrzeugbestand, 2008-2013, https://www.destatis.de/DE/ZahlenFakten/Wirtschaftsbereiche/TransportV erkehr/UnternehmenInfrastrukturFahrzeugbestand/Tabellen/Fahrzeugbesta nd.html 